\title{
Predicting and preventing avoidable hospital admissions: a review
}

\author{
${ }^{1} \mathrm{~S}$ Purdy, ${ }^{2} \mathrm{~A}$ Huntley \\ ${ }^{1}$ Reader in Primary Health Care, ${ }^{2}$ Research Associate, Centre for Academic Primary Care, School for Social and Community Medicine, \\ University of Bristol, UK
}

This review is based in part on a presentation given by Dr Purdy at the Care of the Elderly Symposium on I2
April 2013 at the Royal College of Physicians of Edinburgh

ABSTRACT The strongest risk factors for avoidable hospital admission are age and deprivation but ethnicity, distance to hospital, rurality, lifestyle and meteorological factors are also important, as well as access to primary care. There is still considerable uncertainty around which admissions are avoidable. In terms of services to reduce admissions there is evidence of effectiveness for education, selfmanagement, exercise and rehabilitation, and telemedicine in certain patient populations, mainly respiratory and cardiovascular. Specialist heart failure services and end-of-life care also reduce these admissions. However, case management, specialist clinics, care pathways and guidelines, medication reviews, vaccine programmes and hospital at home do not appear to reduce avoidable admissions. There is insufficient evidence on the role of combinations or coordinated systemwide care services, emergency department interventions, continuity of care, home visits or pay-by-performance schemes. This highlights the importance of robust evaluation of services as they are introduced into health and social care systems.
Correspondence to S Purdy Centre for Academic Primary Care, NIHR School for Primary Care Research, School of Social and Community Medicine University of Bristol

Canynge Hall

39 Whatley Road

Bristol BS8 2PS, UK

tel. +44 (0) II 33 I 4545 e-mail Sarah.Purdy@bristol.ac.uk

KEYWORDS Hospital admissions, older people, systematic reviews

DECLARATION OF INTERESTS No conflicts of interest declared.

\section{INTRODUCTION}

Approximately $40 \%$ of hospital admissions in the United Kingdom are unplanned (20I I/I2).' This paper sets out to summarise research evidence about who is at risk of admission, which admissions are avoidable and which service interventions are effective in reducing emergency admissions. It is based on the results of both systematic reviews and individual studies and has a focus on the care of older adults.

Over the last ten years, emergency admissions have risen by more than a third.' The majority of emergency admissions are in elderly people with co-morbidities; the bed days occupied by those over 75-years-old rose by two-thirds in the last ten years. ${ }^{2}$ At the same time, there are a third fewer general and acute beds than there were 25 years ago.

Some areas are more successful than others in reducing emergency admissions. A five-year analysis of routine data by the Nuffield Trust has yielded some interesting findings behind the rise in admissions. ${ }^{3} \mathrm{On}$ average, emergency admissions rose by $12 \%$ between 2004 and 2009; for some hospitals they fell by up to a third over this period, while in others they almost doubled. Although there has been much debate about the effect of demographics on healthcare use, the ageing population accounted for less than half of the increase in emergency admissions in this study. Of particular note in this analysis was the marked increase in short stay admissions, suggesting changes in clinical thresholds for admission over time and impacts of other initiatives, such as four-hour targets in emergency departments (ED).

In order to try and address this increase in short stay admissions, healthcare organisations in the UK and other countries including the USA, Canada and Australia are trying different care service interventions to prevent and reduce avoidable emergency admissions including risk prediction tools, case management, hospital care at home, telemedicine and different ways of organising acute admissions in hospitals.

\section{WHICH ADMISSIONS ARE AVOIDABLE?}

Ambulatory care sensitive conditions (ACSC) are conditions for which hospital admission could be prevented with care delivered in the primary care setting. The concept originated in the United States, where universal primary healthcare is not available. ${ }^{4}$ Other healthcare systems have adapted the concept and various definitions and sets of ACSCs are in existence. ${ }^{5,6}$ However, there are no absolute categories of avoidable 
admission. For example, it may be appropriate to admit a frail elderly woman with a chest infection who lives on her own in an area without effective intermediate care.

\section{WHO IS MORE LIKELY TO BE ADMITTED?}

The interaction of risk factors for hospital admission is complex but some messages are clear. People who live in deprivation are more likely to be admitted to hospital, with $45 \%$ of the variance across GP practices explained by socio-demographic characteristics. ${ }^{7}$ Even after taking into account other factors, GP practices serving the most deprived quintiles of the population in England have $60-70 \%$ higher rates of admission for asthma, chronic obstructive pulmonary disease (COPD) and respiratory infections compared with those serving the least deprived. ${ }^{8}$ Lower educational achievement is also associated with a higher number of emergency admissions. ${ }^{910}$

Independent of deprivation, those who live in urban areas have higher admission rates than rural areas e.g. $16 \%$ higher rate for asthma, after adjusting for prevalence and deprivation. ${ }^{8}$ Living close to an ED also increases the risk of admission e.g. a 12\% higher rate of asthma admission for each kilometre closer to the ED. ${ }^{8}$

The presence of chronic diseases is independently associated with greater admissions." Lifestyle factors are also important, for example the risk of admission goes up by about $1 \%$ for each $1 \%$ increase in smokers among COPD or asthma patients in a general practice. ${ }^{8}$ The number of previous hospital admissions and length of stay by a patient in the previous year increases admission as does less primary care use. ${ }^{12}$ Other factors that increase risk of emergency admission include meteorological factors and pollution, particularly in respiratory admissions. ${ }^{13}$

\section{HOW GOOD ARE MODELS THAT PREDICT FUTURE EMERGENCY ADMISSIONS?}

There has been a recent growth in the use of predictive modeling to identify people at high risk of future admission. Predictive modelling uses routine data which are entered into a statistical model in order to calculate the risk. ${ }^{14}$ This approach is thought to be the best available predictive technique as it reduces the risk of regression to the mean which is a problem with models that use a simpler threshold or cut-off e.g. people with more than one previous admission in the past 12 months. However, it requires linking datasets, ideally including social care. It is therefore constrained by the range and accuracy of information available in the datasets e.g. data on living alone. The goodness of fit of currently available models ranges from 0.68-0.79 (area under receiver operating characteristic [ROC] curve).$^{13}$ Implementation of a predictive model requires a definition of the risk threshold score. This is the level above which people are to be defined as 'high risk' and above which services or interventions are to be put in place. Assumptions about the potential reduction in emergency admissions and the costs of the additional services required to reduce future admissions need to be as robust as possible when selecting and targeting interventions.

\section{WHAT FEATURES OF GENERAL PRACTICE ARE ASSOCIATED WITH FEWER ADMISSIONS?}

Larger practices have been purported to have lower rates of emergency admissions, as these practices can potentially offer a wider range of services such as acute care services. ${ }^{15}$ Some studies have found that rates of asthma admission may be higher in smaller and singlehanded practices. ${ }^{16-19}$ The same relationship has not been demonstrated for other conditions, for instance COPD and cardiovascular admissions. ${ }^{8,16,20}$ The ratio of patients to practitioners is also a factor, as is the presence of GP trainers within a practice, both of which appear to reduce emergency admissions. ${ }^{20,21}$

One ecological study from the UK has shown that being able to consult a particular GP is associated with lower emergency admission rates, and that greater satisfaction with telephone access is associated with lower ED attendance. ${ }^{22}$ Research conducted in the USA and Canada suggest high continuity of care with a family doctor may be associated with lower risk of admission. ${ }^{23-25}$ A study of a GP service aimed at patients who are referred for urgent medical admission by a GP in the community showed a small reduction in admissions to the medical assessment unit. ${ }^{26}$

\section{OUT-OF-HOURS CARE}

There is some evidence that the rise in emergency admissions in the UK may be partly attributable to changes in out-of-hours provision that occurred in 2004 with the new GP contract. ${ }^{27,28}$ There were also other changes including the introduction of the four-hour waiting time targets in the ED and payment-by-results that have not had an impact. ${ }^{3} \mathrm{~A}$ five-fold variation in outof-hours admission rates has been observed between GPs, suggesting that clinician factors play an important part in determining admission rates. ${ }^{29,30} \mathrm{~A}$ more recent study of clinicians' views found that factors influencing decisions to admit included: distribution of beds between community and sub-acute care, lack of health and social care resources, the admitting (generalist) clinician's lack of knowledge of the patient or condition, communication difficulties between primary and secondary care clinicians, patient preferences and the perceived benefits of admission to hospital. ${ }^{31}$ However, there are also studies that suggest that a GP with specialist knowledge or increased involvement with secondary care can lead to an increased referral rate to the ED. ${ }^{32,33}$ 


\section{QUALITY OF PRIMARY CARE}

Most research does not identify any association between Quality and Outcomes Framework (QOF) scores and hospital admission for patients with asthma, COPD or coronary heart disease. ${ }^{8,34,35}$ However, a more recent longitudinal study suggests that improvements in the quality of diabetes management in general practices were associated with a reduction in admissions. ${ }^{36}$ Medication reviews conducted by pharmacists in the community don't reduce admissions in older patients. ${ }^{37}$

\section{WHICH SERVICE INTERVENTIONS HAVE BEEN EVALUATED?}

\section{Telemedicine}

The evidence around telemedicine is mixed and mainly from the United States. The most compelling evidence showing the impact on reduced health service use was for automated vital signs monitoring and telephone follow-up by nurses, although the cost-effectiveness of interventions is less clear. ${ }^{38}$ Recent UK evidence from the Whole System Demonstrator cluster randomised trial showed no difference in emergency admissions when the analysis adjusted for differences in baseline characteristics. ${ }^{39}$

\section{Case management}

A recent systematic review of the use of case management for reducing admissions in older people identified II randomised controlled trials including a range of case management interventions. Nine of the II trials showed no reduction of emergency hospital admissions with case management compared with usual care. ${ }^{40}$

\section{Home nursing care}

The evidence from a Cochrane review appears stronger for the effect of hospital at home on admission avoidance rather than supported discharge, where costs appeared higher with increased levels of admission compared to hospital care. Outcomes of hospital at home for admission avoidance were similar to inpatient care. ${ }^{41}$ However, a more recent review suggests that the effect of intermediate care especially in the frail elderly is not known. ${ }^{42}$ The outcome of a recent evaluation of virtual wards has yet to be published. ${ }^{43}$

\section{Interventions in the Emergency Department}

All types of assessment and observation wards seem to reduce the number of general ward admissions, but benefits to the patient are unclear. ${ }^{44}$ General practitioners in the ED may result in fewer referrals for admission and cost benefits may exist but the evidence is weak..$^{45}$ One non-randomised study showed that senior clinician review reduced inpatient admissions by $11.9 \%$ and specifically reduced admissions to the acute medical assessment unit by $21.2 \% .^{46}$

\section{Discharge from hospital}

A systematic review showed that structured discharge planning tailored to the individual patient results in fewer readmissions. ${ }^{47}$ Readmissions to hospital were statistically significantly reduced for patients admitted to hospital with a medical diagnosis and who were allocated to discharge planning.

A further systematic review shows that medication review by pharmacists in hospital does not reduce readmissions in general in older patients. ${ }^{37}$ Medication reviews conducted by hospital (seven trials) or community (nine trials) pharmacists did not reduce emergency admissions in the older population. There was some evidence that medication reviews provided by hospital pharmacists pre-discharge with follow-up postdischarge in older people with heart failure (three trials) reduced emergency admissions by $25 \%$.

\section{Preventing readmissions}

Specialist clinics for heart failure reduce admissions after 12 months $^{48}$ and it looks as though heart failure patients do benefit from intensive patient-focused 'transition' case management on discharge. ${ }^{40}$ Pulmonary rehabilitation for COPD works to reduce readmissions. ${ }^{49}$

Exercise-based cardiac rehabilitation for coronary heart disease results in reduced hospital admissions in the shorter term (less than 12 months follow-up). But beyond 12 months there was no significant difference in total hospitalisations. ${ }^{50}$ There is no evidence that emergency hospital admissions are reduced with rehabilitation in stroke or hip fracture patients following surgery. There are limited data on the effect of fall prevention interventions for at-risk elderly patients. The data suggest they did not influence admissions..$^{51-53}$

Self-management with education is effective for patients with COPD. ${ }^{54}$ The studies show a significant reduction in the probability of at least one hospital admission among patients receiving self-management education compared to those receiving usual care. In a Cochrane review of education for coronary heart disease patients overall, no reduction in risk of emergency hospital admissions was seen. ${ }^{55}$ A systematic review on education for heart failure patients included a total of 2,686 patients in 19 randomised controlled trials; 15 demonstrated a significant effect from their intervention in at least one of their outcome measures, but there was weak evidence for its effect on emergency admissions. ${ }^{56}$

\section{Care at the end of life}

Early palliative care could reduce admissions and deaths in hospital. For example one study from the USA examined the effect of introducing palliative care early after diagnosis among ambulatory patients with newly diagnosed metastatic non-small-cell lung cancer and looked at patient reported outcomes and end-of-life 
care use. The number of deaths in hospital was lower among those with early introduction of palliative care. ${ }^{57}$

The coordination of end-of-life care also reduces admissions. An evaluation of the Marie Curie Delivering Choice Programme found that service users were $67 \%$ less likely to die in hospital and were $5 \mathrm{I} \%$ less likely to have an emergency hospital admission in the last month of life. ${ }^{58}$

\section{Integration of care}

A recent evaluation of 16 integrated care pilot programmes in the UK (mainly horizontal integration of health and social care) found no evidence of an anticipated general reduction in emergency admissions but there were reductions in planned admissions and in outpatient attendance. ${ }^{59}$

\section{REFERENCES}

I Health \& Social Care Information Centre. Hospital episode statistics 20I //I2 [Internet]. Leeds: HSCIC; 2012 [cited 20I3 April 26]. Available from: http://www.hesonline.org.uk

2 Royal College of Physicians. Hospitals on the edge? The time for action [Internet]. London: Royal College of Physicians; 2012 [cited 2013 June 14]. Available from: http://www.rcplondon.ac.uk/sites/ default/files/documents/hospitals-on-the-edge-report.pdt

3 Blunt I, Bardsley M, Dixon J. Trends in emergency admissions in England 2004-2009: is greater efficiency breeding inefficiency? [Internet]. London: Nuffield Trust; 2010 [cited 2013 June 14] Available from: http://nuffield.dh.bytemark.co.uk/sites/files/nuffield/ publication/Trends in emergency admissions BRIEFING.pdf

4 Bindman A, Grumbach K, Osmond D et al. Preventable hospitalizations and access to health care. JAMA 1995; 274:305-II. http://dx.doi.org/I0.I 00 I/jama.1995.03530040033037

5 Purdy S, Griffin T, Salisbury C et al. Ambulatory care sensitive conditions: terminology and disease coding need to be more specific to aid policy makers and clinicians. Public Health 2009; 123:169-73. http://dx.doi.org/10.1016/j.puhe.2008.II.00I

6 NHS Institute for Innovation and Improvement. Directory of ambulatory emergency care for adults. London: NHS; 2010.

7 Reid FD, Cook DG, Majeed A. Explaining variation in hospital admission rates between general practices: cross sectional study. BMJ 1999; 319:98-103. http://dx.doi.org//0.II36/bmj.319.7202.98

8 Purdy S, Griffin T, Salisbury C et al. Emergency respiratory admissions: influence of practice, population and hospital factors. J Health Serv Res Policy 20I I; 16:133-40. http://dx.doi.org/I0.1258/ jhsrp.2010.010013

9 Carlsen, F, Grytten J, Kjelvik J et al. Better primary physician services lead to fewer hospital admissions. Eur J Health Econ 2007, 8:I7-24. http://dx.doi.org/10.1007/s10198-006-000I-x

10 Magan P, Alberquilla A, Otero A et al. Hospitalizations for ambulatory care sensitive conditions and quality of primary care: their relation with socioeconomic and health care variables in the Madrid regional health service (Spain). Med Care 20II; 49:17-23. http://dx.doi.org/I0.1097/MLR.0b0 I3e318I ef9dI3

II Ricketts TC, Randolph R, Howard HA et al. Hospitalization rates as indicators of access to primary care. Health Place 200 I; 7:27-38. http://dx.doi.org/I0.1016/SI353-8292(00)00035-6

12 Rizza P, Bianco A, Pavia M et al. Preventable hospitalization and acess to primary health care in an area of Southern Italy. BMC Health Serv Res 2007; 7:I34. http://dx.doi.org// 0.I I86//472-6963-7-I34

\section{CONCLUSION}

There are some evidenced-based service interventions that reduce generic admissions. These include: continuity of care with a GP, early senior review in the ED, structured discharge planning and advanced care planning and coordination of care at the end of life. In addition, there is some good evidence on services that reduce respiratory and cardiac admissions including: selfmanagement in COPD and adults with asthma, especially if this includes a self-management plan, pulmonary rehabilitation in COPD, specialist clinics in heart failure and exercise-based cardiac rehabilitation in the shortterm. The lack of effective interventions and the lack of good data about combinations of interventions highlight the importance of robust evaluation of services as they are introduced into health and social care systems

I3 Purdy S. Avoiding hospital admissions: What does the research evidence say? [Internet]. London:The King's Fund; 2010 [cited 2013 June 14]. Available from: http://www.kingsfund.org.uk/publications/avoiding _ hospital.html

I4 Lewis G, Curry N, Bardsley M. Choosing a predictive risk model: a guide for commissioners in England [Internet]. London: Nuffield Trust; 2011 [cited 2013 June 14]. Available from: http://www. nuffieldtrust.org.uk/sites/files/nuffield/publication/choosing predictive risk model guide for commissioners novl I.pdf

15 The NHS Confederation. Ideas from Darzi: polyclinics [Internet]. London: NHS Confederation; 2008 [cited 2013 June 14]. Available from: http://www.nhsconfed.org/Publications/Documents/ Ideas\%20from\%20Darzi\%20Polyclinics.pdf

16 Saxena S, George J, Barber J et al. Association of population and practice factors with potentially avoidable admission rates for chronic diseases in London: cross sectional analysis. J $R$ Soc Med 2006; 99:8I-9. http://dx.doi.org/I0.1258/jrsm.99.2.8I

17 Griffiths C, Kaur G, Gantley M et al. Influences on hospital admission for asthma in south Asian and white adults: qualitative interview study. BMJ 200I: 323; 962-6. http://dx.doi.org/I0.I I36/bmj.323.7319.962

18 Griffiths C, Sturdy P, Naish J et al. Hospital admissions for asthma in East London: associations with characteristics of local general practices, prescribing, and population. BMJ 1997; 314:482-6. http:// dx.doi.org/I0.II36/bmj.314.7079.482

19 Yeung S, MacLeod M, Sutton M. Population, practice and hospital influences on emergency admissions for chronic conditions. Scotland: NHS Quality Improvement; 2005.

20 Purdy S, Griffin T, Salisbury C et al. Emergency admissions for coronary heart disease: a cross-sectional study of general practice, population and hospital factors in England. Public Health 20II; I25:46-54. http://dx.doi.org//0.1016/j.puhe.2010.07.006

2I Majeed A, Bardsley M, Morgan D et al. Cross sectional study of primary care groups in London: association of measures of socioeconomic and health status with hospital admission rates. BMJ 2000; 321:1057-60. http://dx.doi.org/l0.1 I36/bmj.32I.7268.1057

22 Bankart MJ, Baker R, Rashid A et al. Characteristics of general practices associated with emergency admission rates to hospital: a cross-sectional study. Emerg Med J 20II; 28: 558-63. http:// dx.doi.org/10.1136/emj.2010.108548

23 Menec VH, Sirski M, Attawar D et al. Does continuity of care with a family physician reduce hospitalizations among older adults? J Health Serv Res Policy 2006; II:196-20I. http://dx.doi. org/I0.1258//3558/906778476562 
24 Christakis DA, Mell L, Koepsell TD et al. Association of lower continuity of care with greater risk of emergency department use and hospitalization in children. Pediatrics 2001; 107:524-9. http:// dx.doi.org/I0.1542/peds. 107.3.524

25 Gill JM, Mainous AG 3rd. The role of provider continuity in preventing hospitalizations. Arch Fam Med 1998; 7:352-7. http:// dx.doi.org/I0.100I/archfami.7.4.352

26 Rogers S, Wilson D, Wan S et al. Medication-related admissions in older people: a cross-sectional, observational study. Drugs Aging 2009; 26:95 I-61. http://dx.doi.org//0.2165/II316750-000000000-00000

27 Thompson C, Hayhurst C, Boyle A. How have changes to out-ofhours primary care services since 2004 affected emergency department attendances at a UK District General Hospital? A longitudinal study. Emerg Med J 2010; 27:22-5. http://dx.doi. org/I0.1 I36/emj.2008.0688I7

28 Saxena S, Bottle A, Gilbert R et al. Increasing short-stay unplanned hospital admissions among children in England; time trends analysis '97-'06.PLoS ONE 2009; 4:e7484.http://dx.doi.org//0.137I/ journal.pone.0007484

29 Rossdale M, Kemple T, Payne $S$ et al. An observational study of variation in GPs' out-of-hours emergency referrals. $\mathrm{Br} J \mathrm{Gen}$ Pract 2007; 57: 152-4.

30 Calnan M, Payne S, Kemple T et al. A qualitative study exploring variations in GPs' out-of-hours referrals to hospital. Br J Gen Pract 2007; 57:706-13.

31 Hammond CL, Pinnington LL, Phillips MF. A qualitative examination of inappropriate hospital admissions and lengths of stay. BMC Health Serv Res 2009; 9:44. http://dx.doi.org// 0.I I 86//472-6963-9-44

32 Lowe RA, Localio, AR Schwarz DF et al. Association between primary care practice characteristics and emergency department use in a medicaid managed care organization. Med Care 2005; 43:792-800. http://dx.doi.org//0.1097/0I.mlr.0000 I704/3.60054.54

33 McCusker J, Tousignant P, Borges Da Silva R et al. Factors predicting patient use of the emergency department: A retrospective cohort study. CMAJ 2012; 184:E307-16. http://dx. doi.org/I0.1503/cmaj.III069

34 Downing A, Rudge G, Cheng Y, et al. Do the UK government's new Quality and Outcomes Framework (QOF) scores adequately measure primary care performance? A cross-sectional survey of routine healthcare data. BMC Health Serv Res 2007; 7:166. http:// dx.doi.org//0.1/86//472-6963-7-166

35 Bottle A, Millett C, XieY et al. Quality of primary care and hospital admissions for diabetes mellitus in England. J Ambul Care Manage 2008; 31:226-38.

36 Dusheiko M, Doran T, Gravelle $\mathrm{H}$ et al. Does higher quality of diabetes management in family practice reduce unplanned hospital admissions? Health Serv Res 20II; 46:27-46. http://dx.doi. org/I0.1III/j. I475-6773.2010.0II84.x

37 Purdy S, Paranjothy S, Huntley A et al. Interventions to reduce unplanned hospital admission: a series of systematic reviews [Internet]. Bristol: NHS Bristol; 2012 [cited 2013 June 14] Available from: www.bristol.ac.uk/primaryhealthcare/docs/ projects/unplannedadmissions.pdf

38 McLean S, Protti D, Sheikh A. Telehealthcare for long term conditions. BMJ 20I I; 342:d I20. http://dx.doi.org/l0.1 I36/bmj.dI 20

39 Steventon A, Bardsley M, Billings J et al. Effect of telehealth on use of secondary care and mortality: findings from the Whole System Demonstrator cluster randomised trial. BMJ 2012; 344:e3874. http://dx.doi.org//0.I I36/bmj.e3874

40 Huntley A, Thomas RL, Mann M et al. Is case management effective in reducing the risk of unplanned hospital admissions for older people? A systematic review and meta-analysis. Fam Pract 2013; 30:266-75. http://dx.doi.org//0.1093/fampra/cms081

4I Shepperd S, Wee B, Straus SE. Hospital at home: home-based end of life care. Cochrane Database Syst Rev 20I I; 7:CD00923I.
42 Pearson $\mathrm{M}$, Hunt $\mathrm{H}$, Cooper $\mathrm{C}$ et al. Intermediate care: a realist review and conceptual framework [Internet]. London: NIHR; 2013 [cited 2013 June 14]. Available from: http://www.netscc.ac.uk/hsdr/ projdetails.php?ref $=10-1012-07$

43 Lewis G, Dixon J, Bardsley M et al. Analysis of virtual wards: a multidisciplinary form of case management that integrates social and health care [Internet]. London: NIHR; 2013 [cited 2013 June 14]. Available from: http://www.netscc.ac.uk/hsdr/projdetails. php?ref=09-|8|6-102|

44 Cooke MW, Higgins J, Kidd P. Use of emergency observation and assessment wards: a systematic literature review. Emerg Med J 2003; 20:138-42. http://dx.doi.org//0.1 I36/emj.20.2.138

45 Carson D, Clay H, Stern R. Primary care and emergency departments report from the Primary Care Foundation March 2010 [Internet]. East Sussex: PCF; 2010 [cited 2013 June 14]. Available from: https:// secure.collemergencymed.ac.uk/asp/document.asp?!D $=5260$

46 White AL, Armstrong PA, Thakore S. Impact of senior clinical review on patient disposition from the emergency department. Emerg Med J 2010; 27:262-5, 296. http://dx.doi.org//0.1/36/ emj.2009.077842

47 Shepperd S, McClaran J, Phillips CO et al. Discharge planning from hospital to home. Cochrane Database Syst Rev 20 I0; I:CD0003। 3.

48 Thomas R, Huntley A, Mann M et al. Specialist clinics for reducing emergency admissions in patients with heart failure: a systematic review and meta-analysis of randomised controlled trials. Heart 2013; 99:233-9. http://dx.doi.org//0.1 I36/heartjnl-2012-3023 I3

49 Puhan M, Scharplatz M, Troosters T et al. Pulmonary rehabilitation following exacerbations of chronic obstructive pulmonary disease. Cochrane Database Syst Rev 2009; I:CD005305.

50 Heran BS, Chen JM, Ebrahim $S$ et al. Exercise-based cardiac rehabilitation for coronary heart disease. Cochrane Database Syst Rev 201 I; 7:CD00I800.

5I Gillespie LD, Robertson MC, Gillespie WJ et al. Interventions for preventing falls in older people living in the community. Cochrane Database Syst Rev 2009; 2:CD007I46.

52 McClure R, Turner C, Peel N et al. Population-based interventions for the prevention of fall-related injuries in older people. Cochrane Database Syst Rev 2005; I:CD00444I.

53 Cameron ID, Murray GR, Gillespie LD et al. Interventions for preventing falls in older people in nursing care facilities and hospitals. Cochrane Database Syst Rev 20 I0; I:CD005465.

54 Effing T, Monninkhof EM, van der Valk PD et al. Self-management education for patients with chronic obstructive pulmonary disease. Cochrane Database Syst Rev 2007; 4:CD002990.

55 Brown JP, Clark AM, Dalal $\mathrm{H}$ et al. Patient education in the management of coronary heart disease. Cochrane Database Syst Rev 201 I; I2:CD008895.

56 Boyde M,Turner C, Thompson DR et al. Educational interventions for patients with heart failure: a systematic review of randomized controlled trials.J Cardiovasc Nurs 201 I; 26:E27-35.

57 Temel JS, Greer JA, Muzikansky A et al. Early palliative care for patients with metastatic non-small-cell lung cancer. $N$ Engl J Med 2010; 363:733-42. http://dx.doi.org//0.1056/NEJMoal 000678

58 Wye L, Lasseter G, Percival J et al. Independent evaluation of the Marie Curie Cancer Care Delivering Choice programme in Somerset and North Somerset. Final report October 2012 [Internet]. Bristol: Centre for Primary Health Care; 2012 [cited 2013 June 14]. Available from: http://www.mariecurie.org.uk/Documents/ HEALTHCARE-PROFESSIONALS/commissioning-services/ Delivering-Choice-Proramme-in-Somerset-and-North-SomersetFinal-Report.pdf

59 RAND Europe, Ernst \& Young LLP. National evaluation of the Department of Health integrated care pilots [Internet]. California: RAND Corporation; 2012 [cited 2013 June 14]. Available from: http://www.rand.org/content/dam/rand/pubs/technical_ reports/20I2/RAND_TRII64.pdf 